\title{
Linking vegetation cover patterns to hydrological responses using two process-based pattern indices at the plot scale
}

\author{
LIU Yu ${ }^{1,2}$, FU BoJie $^{1^{*}}$, LÜ YiHe $^{1}$, GAO GuangYao ${ }^{1}$, WANG Shuai ${ }^{1} \& \mathrm{ZHOU} \mathrm{Ji}^{1}$ \\ ${ }^{1}$ State Key Laboratory of Urban and Regional Ecology, Research Center for Eco-Environmental Sciences, \\ Chinese Academy of Sciences, Beijing 100085, China; \\ ${ }^{2}$ Laboratory of Digital Earth Sciences, Institute of Remote Sensing and Digital Earth, \\ Chinese Academy of Sciences, Beijing 100101, China
}

Received December 5, 2012; accepted March 4, 2013; published online May 27, 2013

\begin{abstract}
Vegetation cover pattern is one of the factors controlling hydrological processes. Spatially distributed models are the primary tools previously applied to document the effect of vegetation cover patterns on runoff and soil erosion. Models provide precise estimations of runoff and sediment yields for a given vegetation cover pattern. However, difficulties in parameterization and the problematic explanation of the causes of runoff and sedimentation rates variation weaken prediction capability of these models. Landscape pattern analysis employing pattern indices based on runoff and soil erosion mechanism provides new tools for finding a solution. In this study, the vegetation cover pattern was linked with runoff and soil erosion by two previously developed pattern indices, which were modified in this study, the Directional Leakiness Index (DLI) and Flowlength. Although they use different formats, both indices involve connectivity of sources areas (interpatch bare areas). The indices were revised by bringing in the functional heterogeneity of the plant cover types and the landscape position. Using both artificial and field verified vegetation cover maps, observed runoff and sediment production on experiment plots, we tested the indices' efficiency and compared the indices with their antecedents. The results illustrate that the modified indices are more effective in indicating runoff at the plot/hillslope scale than their antecedents. However, sediment export levels are not provided by the modified indices. This can be attributed to multi-factor interaction on the hydrological process, the feedback mechanism between the hydrological function of cover patterns and threshold phenomena in hydrological processes.
\end{abstract}

cover pattern indices, runoff, soil erosion, vegetation cover pattern

Citation: $\quad$ Liu Y, Fu B J, LÜ Y H, et al. Linking vegetation cover patterns to hydrological responses using two process-based pattern indices at the plot scale. Science China: Earth Sciences, 2013, 56: 1888-1898, doi: 10.1007/s11430-013-4626-1

Water movement and sediment transport across landscapes are critical processes occurring on the earth's surface with a large amount of mass flux and extensive environmental and social consequences (Pimentel and Kounang, 1998). Spatial patterns of landscape factors such as vegetation cover pattern effectively alter the behavior of material flows across the landscape. Linking soil erosion processes with vegetation cover patterns has attracted much attention in recent decades and the subject has become a hot topic for current

*Corresponding author (email: bfu@rcees.ac.cn) research (Cerdà, 2007; Boer and Puigdefábregas, 2005; Sommer, 2006; Van Rompaey et al., 2007; Van dessel et al., 2008; Ouyang et al., 2010). Field monitoring and modeling are the main approaches used in studies focusing on pattern-process relationships for runoff and soil erosion. In targeting this issue, a large number of field measurements have been designed in terrestrial landscapes at scales ranging from plot/hillslope to watershed, as well as at the landscape level (Boer and Puigdefábregas, 2005; Bautista et al., 2007; Ludwig et al., 2007; Mayor et al., 2008). Various spatially distributed models were developed to evaluate the 
consequences of vegetation cover pattern change on runoff and soil erosion (e.g., LISEM (Jetten and de Roo, 2001)). After a complicated system of parameterization and validation using outlet data, most of these models can predict runoff and sediment output at the outlet of a specific watershed with an acceptable accuracy. However, since usually only outlet data are available, there are uncertainties in the calibration/validation and parameterization of these models (Quinton, 1997; Richard et al., 2000). Though many models can generate a precise estimate of runoff and sediment output at an outlet, the explanation of the causes are problematic since validations of spatially distributed models are based on outlet data (Jetten et al., 2003). A validation based on outlet data is not reliable as it fails to disclose the spatially distributed causes based on process regimes, which leads to "ending up with the correct result for the wrong reasons" (Boardman, 2006). Spatially distributed data are the best choice (Takken et al., 1999; Jetten et al., 2003). However, collection of spatially distributed runoff and soil erosion data for model calibration/validation, especially for those modeling using individual events, is expensive and creates difficulties for observation design.

By delineating the landscape pattern to indicate the process response to landscape pattern dynamics, landscape indices provide a simple tool to link the landscape pattern with runoff and soil erosion (Ludwig et al., 2002; Imeson and Prinsen, 2004; Fu et al., 2006; Mayor et al., 2008). Compared to hydrological and soil erosion models, landscape pattern indices indicate the effect of landscape factors on the processes by quantifying the spatial pattern and are cost effective and easy to use (Zhao et al., 2012). Classifying the landscape into vegetation patches and inter-patch bare areas is common when describing landscape patterns using landscape indices. The vegetation patch can significantly increase the soil infiltration rate (Ludwig et al., 2005), enhance the soil anti-erodibility (Zuazo and Pleguezuelo, 2008), reduce rainfall erosion (Vasquez-Mendez et al., 2010), and effectively intercept runoff and sediments from upslope (Molina et al., 2009; Yuan et al., 2009). In the process of runoff and sediment generation, vegetation patches act as 'sinks', while bare soil acts as 'source' areas (Ludwig et al., 2005). Connectivity of source areas is among the most effective landscape characteristic controlling runoff generation and soil erosion (Cammeraat, 2004; Mayor et al., 2008). Well-connected source areas produce more runoff and sediment than those with low connectivity. However, connectivity remains difficult to describe in most models (de Vente et al., 2006). Indicating landscape connectivity using landscape indices makes sense in efforts to represent the potential of a given landscape pattern to reduce or enhance runoff and soil erosion (Mayor et al., 2008; Borselli et al., 2008).

Ludwig et al. (2002) developed the Directional Leakiness Index $(D L I)$ to represent the potential of a given hillslope vegetation pattern to retain materials (e.g., soil particles and water). Mayor et al. (2008) produced the Flowlength index that delineates the pathway length of water flow from each location to sinks such as vegetation patches and topographical depressions (ponds). By using different formats, both indices use the concept of connectivity. These two indices are meaningful for predicting the hydrological effect of vegetation cover pattern. However, the indices omit some information concerning the function of cover patterns and their impact on the processes of runoff and soil erosion, which weakens their effectiveness. The influence of the functional heterogeneity in vegetation cover on hydrological processes was neglected. As illustrated by recent studies (Quinton et al., 1997; Molina et al., 2007), different vegetation cover types have different capabilities to trap water and sediment. In addition, landscape position was not considered, even though it is an important factor affecting material delivery to the outlet. Intuitively, the closer a source area is to the outlet, the easier it is for material to reach the outlet. The objective of this study is to improve the ability of these two indices to link landscape patterns with runoff and soil erosion at a hillslope scale. Quantifying the functional heterogeneity of vegetation cover in hydrological processes was involved in this modification. The runoff and soil erosion data obtained from field experiment in the Loess Plateau were used to test the efficiency of these indices.

\section{Methods and materials}

\subsection{Cover pattern measurement}

In this study, two landscape indices, the Directional Leakiness Index (DLI) (Ludwig et al., 2002) and Flowlength index (Mayor et al., 2008), related to the connectivity of source areas were employed to measure the cover pattern at the plot scale. By using different algorithms, both of these two indices indicate vegetation cover patterns by measuring connectivity of runoff and sediment source areas structurally.

Flowlength characterizes the connectivity between runoff and sediment source areas (bare areas) based on a binary raster map of vegetation cover and topography. It delineates the connectivity of source areas by measuring the potential surface path length of water flow starting from a given location along the topographic gradient until it meets the sink cover type. Vegetation patches and ponds are regarded as the sinks of runoff and sediment. The potential path length is defined by a single flow direction approach and starts from each source grid cell (as illustrated in Figure 1). The vegetation patches and ponds are considered to be the terminal of the path. The longer the path, the higher the source area connectivity is.

The Directional Leakiness Index $(D L I)$ describes the spatial distribution of vegetation patches to characterize the potential of a specific cover pattern to retain matter (e.g., runoff and sediment) at the plot or hillslope scale (Ludwig 


\begin{tabular}{|c|c|c|c|c|c|c|c|c|c|c|c|c|c|c|}
\hline & \multicolumn{7}{|c|}{ (a) } & \multicolumn{7}{|c|}{ (b) } \\
\hline & 0 & 1 & 2 & 3 & 4 & 5 & 6 & 0 & 1 & 2 & 3 & 4 & 5 & 6 \\
\hline 0 & 8 & 8 & 8 & 8 & 9 & 8 & 8 & 0 & 0 & 0 & 0 & 11.9 & 10.4 & 0 \\
\hline 1 & 7 & 7 & 7 & 7 & 9 & 7 & 7 & 0 & 0 & 0 & 0 & 0 & 9 & 9.2 \\
\hline 2 & 6 & 6 & 6 & 6 & 6 & 5 & 7 & 3.2 & 3.4 & 3.3 & 3.2 & 3.3 & 6.8 & 8.7 \\
\hline 3 & 4 & 5 & 5 & 3 & 5 & 4 & 7 & 1 & 0 & 2.2 & 0 & 2.2 & 5.4 & 0 \\
\hline 4 & 4 & 5 & 4 & 5 & 4 & 6 & 5 & 0 & 0 & 2.4 & 5 & 4 & 5.4 & 4.7 \\
\hline 5 & 3 & 3 & 3 & 3 & 2 & 3 & 3 & 0 & 0 & 0 & 3.1 & 1.7 & 2.2 & 2.4 \\
\hline 6 & 2 & 2 & 2 & 3 & 4 & 1 & 3 & 1 & 0 & 0 & 1.4 & 3.2 & 0 & 0 \\
\hline
\end{tabular}

Figure 1 Schematic diagram for the calculation of Flowlength index following Mayor et al. (2008). Grey squares indicate vegetation patches; the numbers in (a) are the elevation, and in (b) the Flowlength; $d$ is the horizontal distance of grids whose diagonal lines are adjacent; $x$ and $y$ are the horizontal distances of grids whose horizontal and vertical lines are adjacent. $d=$ grid size $\times \sqrt{2}$.

et al., 2002). DLI was developed with several premises. The first premise is there are two types of landscapes with apparently contrasting hydrological functions, bare area (or interpatch area) and vegetation patch. Secondly, matter flow direction was known. In water-erosion dominated settings, flow direction is down slope. Third, the relief was uniform within a single rectangular plot. Vegetation arrangement pattern was the only factor considered in DLI. Vegetation patches were considered as sinks of resources and bare areas the source. The number of source grid cells that connect together along the flow direction without interruption by a sink grid cell is the key variable involved in indicating the retention capability. Three parameters were calculated for each column in the binary raster map of vegetation distribution: distance of the first vegetation patch to the top of plot/hillslope $(d t)$, to the bottom $(d b)$, and interval between vegetation patches $(d p)$ (Figure 2). For convenience of comparisons among plots with different sizes, the index was scaled to a standard plot whose size depends on the cell size of the plot to be evaluated. The following formulas were used to calculate $D L I$.

$$
\begin{gathered}
D L I=1-\left[\left(L_{\max }-L_{\mathrm{obs}}\right) /\left(L_{\max }-L_{\min }\right)\right]^{k}, \\
L_{\mathrm{obs}}=\sum_{j}\left[\left(h_{s} / h_{j}\right)\left(\sum_{i} d p_{i, j}^{2}\right)+\left(\left(h_{s} / h_{j}\right)-1\right)\left(d t_{j}+d b_{j}\right)^{2}\right. \\
\left.+\left(d t_{j}^{2}+d b_{j}^{2}\right)\right]\left(w_{s} / w_{m}\right) p d .
\end{gathered}
$$

In Figure 2, $i$ and $j$ are the row and column numbers, respectively; $h_{s}, w_{s}, h_{j}$, and $w_{m}$ are the height and width of the standard area (in $\mathrm{m}$ ), the column height and the map width of the sample area (in $\mathrm{m}$ ), respectively.

However, as noted above, vegetation patches are not absolute sinks. There is runoff generation and sediment export

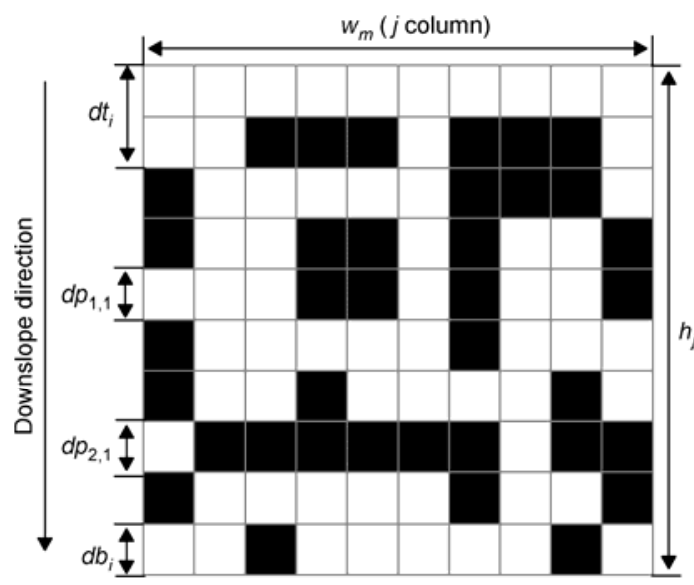

Figure 2 Schematic diagram of parameters for DLI revised from (Ludwig et al., 2002).

from vegetation patches, although it is rather low compared to that of bare soil. In addition, the position of source areas is an important factor in the hydrological process (Rey, 2004; Bracken and Croke, 2007). Serious soil erosion will occur in the source areas with a larger runoff supply area in the upper slope. The distance of source areas to the outlet significantly affects the total runoff and sediment that can be observed at the outlet. In this study, the shortcomings of Flowlength and DLI mentioned above were corrected by bringing in the weight coefficient $(\omega)$ indicating runoff and sediment generation potential of each cover type compared to bare soil and considering the distance $(F l)$ to the outlet. For convenience, the modified version of Flowlength and $D L I$ are named Flowlength_M and DLI_M. $\omega$ is defined in eq. (3). 


$$
\omega=\alpha \times(1-c / 100) \times \sin (\theta) .
$$

where $\alpha$ stands for capacity of vegetation type to retain water and soil. $\alpha$ was determined by the ratio of the runoff coefficient of a micro plot with a given cover type compared to a plot with bare soil in this study. $c$ is the percent vegetation coverage. $\theta$ is the slope gradient. $F l$ is the flow path length to the outlet of each location with each segment weighted by $\omega$ (Figure 3 ). Since the calculation used a raster map, the inverse of $\mathrm{Fl}^{2}$ was used as a distance weight for each grid cell. The weight $(W)$ for each grid cell is the product of the inverse distance weight and $\omega$, the weight for hydrological function.

$$
W=\omega \times\left(1 / F l^{2}\right) .
$$

In calculation of $D L I \_\mathrm{M}$, the $d t, d b, d p, h_{j}$ of $D L I$ were used in weighted form ( $d t_{-} \mathrm{M}, d b_{-} \mathrm{M}, d p \_\mathrm{M}$ and $\left.h_{j} \_\mathrm{M}\right) . d t \_\mathrm{M}$, $d b \_\mathrm{M}$ and $d p \_\mathrm{M}$ are weighted flow path lengths from the plot's upper edge to the first vegetation patch, from the last vegetation patch to the plot's lower edge and between vegetation patches, respectively. $h_{j} \mathrm{M}$ is the height of column $j$ measured using flow path length weighted by $W$. For Flow-
length_M, the length of the segment of a flow path within a grid cell was weighted by multiplying the length by $W$.

\subsection{Runoff and soil erosion observation}

\subsubsection{Description of the study site}

This field experiment was conducted in the Yangjuangou catchment near Yan An, which is located in the Hilly and Gully Region of the Loess Plateau. The slope gradient of the Yangjuangou catchment ranges from 10 to $30^{\circ}$ (Li et al., 2003). This area has a semi-arid continental climate with an average annual rainfall of $535 \mathrm{~mm}$. Rainfall events occur mainly between June and September with large inter-annual variations. The soil is a Calcaric Cambisol characterized by a uniform texture, weak structure and is highly erodible by water ( $\mathrm{Li}$ et al., 2003). The dominant natural grasses are Artemisia sacrorum, Stipa bungeana and Artemisia scoparia. Prunus armeniaca and Hippophae rhamnoides are the main shrub species. A mosaic of patchy land cover, comprised of areas with different revegetation times and soil properties, is the typical landscape pattern in the Yangjuangou catchment as a result of human disturbances as well as climatic

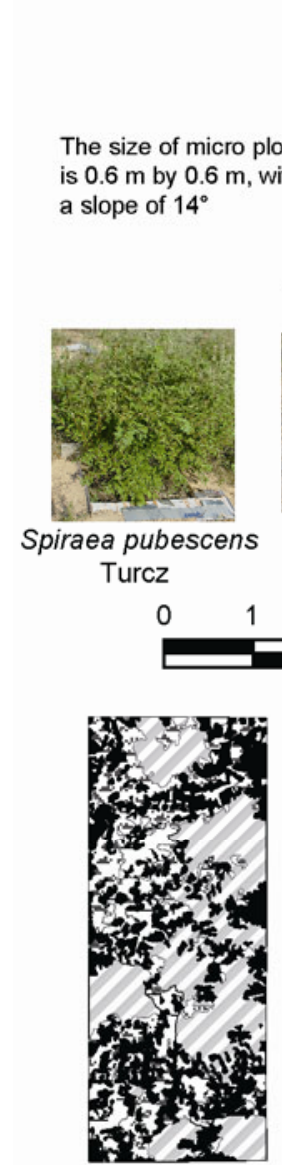

Plot 1

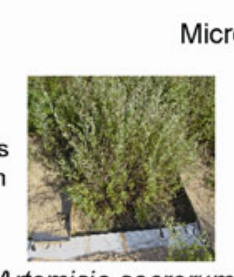

Artemisia sacrorum

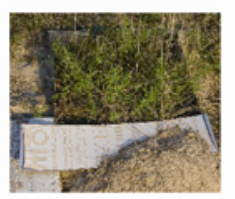

Beard grass

$2 \mathrm{~m}$

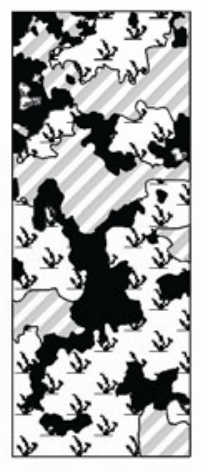

Plot 2
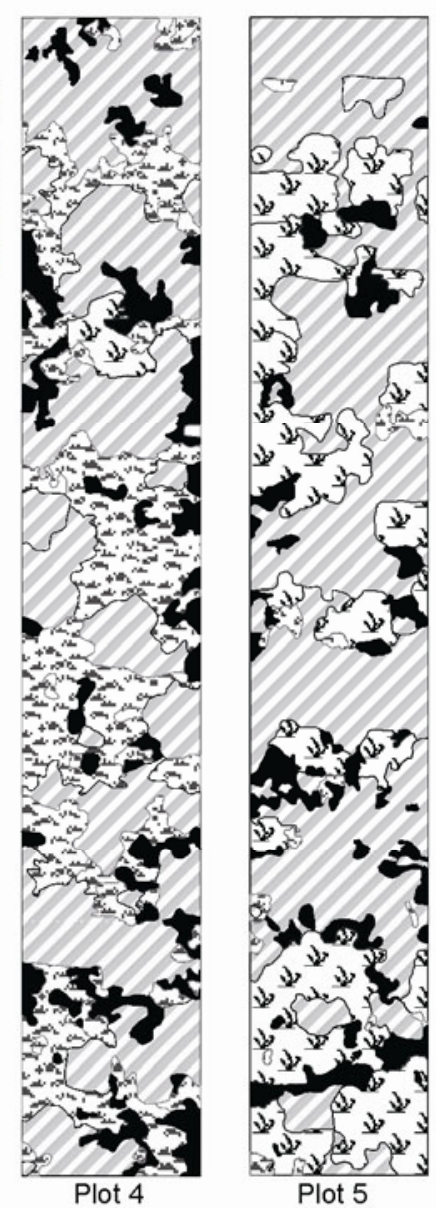

Plot 4

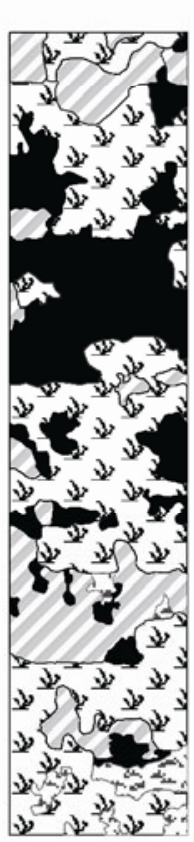

Plot 3

Spiraea pubescens Turcz

Figure 3 Vegetation distribution map of runoff plots and pictures of micro plots. 
and topographical conditions (Liu et al., 2012).

\subsubsection{Observation methods}

Two types of experiment plot were set up for this study on a northwest hillslope, where cropland had been abandoned and revegetated for 25 years. One is mosaic plot covered by a mosaic of different vegetation patches and interpatch bare area (MP for short). Another type is single-cover-type and micro size plot (SP for short). Five MPs with an area over $10 \mathrm{~m}^{2}$, a slope gradient about $22^{\circ}$ and covered by spare vegetation were set up. All the MPs have a same width of $2 \mathrm{~m}$. The lengths of the MPs range from 5 to $13 \mathrm{~m}$ : two plots have a length of $5 \mathrm{~m}$; one plot is $9 \mathrm{~m}$ in length; and the other two has a length of $13 \mathrm{~m}$. For MPs, the vegetation distributions were mapped from photographs (Liu et al., 2012). The minimum patch for inclusion on the map was $5 \mathrm{~cm} \times 5 \mathrm{~cm}$. Four cover types were classified in MPs: bare soil, Artemisia sacrorum, Spiraea pubescens Turcz, and beard grass. A $5 \mathrm{~cm} \times 5 \mathrm{~cm}$ grid cell size was used to produce raster maps of percent vegetation cover (Figure 3 ). SPs have a size of 60 $\mathrm{cm} \times 60 \mathrm{~cm}$. Three SPs were constructed near the MPs for each of the four cover types indentified in MPs to quantify the water and soil retention function (Figure 3). Runoff volume and sediment export were gauged by event both for MPs and for SPs. The rainfall depth was recorded to an accuracy of $0.2 \mathrm{~mm}$ using a tipping bucket rain gauge that was connected to a data logger and positioned at the open area of the experiment site. Mean rainfall intensity and duration was calculated for each rainfall event. In the beginning of the experiment, the soil samples of plots other than the micro plots were collected for soil physical and chemical properties analysis. The texture and content of organic carbon and nitrogen were tested. During the observation period, soil moisture of MPs with a depth of $40 \mathrm{~cm}$ was monitored every 4 days regularly. Before and after each rainfall event, additional soil moisture observations were conducted.

\subsection{Data analysis}

The weight coefficients of the three cover types of vegetation are the ratios of the average runoff coefficient of the corresponding micro plots to that of the micro plots with bare soil. The weight coefficient of bare soil was set as one, i.e., the runoff potential of a micro plot covered by bare soil was the highest. Correlation between cover pattern and hy- drological variables was explored using Person's correlation supported by SPSS Statistics11 (SPSS Inc., Chicago, Illinois, USA). Plot map processing was aided by Arcgis 9.0 (ESRI Inc., California, USA). Calculation of DLI and DLI_M was carried out in Matlab 7.0. Flowlength and Flowlength_M were computed using a procedure developed in Arc/info 8.1 (Environmental Systems Research Institute Inc., Redlands, CA, USA) with Arc Macro Language (AML).

\section{Results}

\subsection{Vegetation cover patterns, runoff, and soil erosion}

Of all the five MPs with vegetation cover mapped (Figure 3 ), the coverage ranged from $68.9 \%$ to $92.1 \%$ (Table 1). All plots have a high vegetation cover and apparently different cover patterns. Bare soil in plot 1 is the most fragmented, followed by plots 4 and 5 . In plots 2 and 3, the bare soil patches are more aggregated. Artemisia sacrorum appeared in all the MPs and dominated plots 1, 4, and 5. Highly aggregated Spiraea pubescens Turcz patches appeared in plots 2, 3 and 5 and contributed the largest portion of cover to plots 2 and 3. Farming stopped on all the plots at the same time, about 25 years ago. Soil properties are similar in the five MPs (Table 1).

Among the SPs with single cover types, the slope varied slightly (ranging from $14^{\circ}$ to $19^{\circ}$ ). Except for those with bare soil, vegetation coverage of all SPs is higher than $70 \%$ (Table 2), and the sediment export from these vegetated micro plots was negligible (Morgan, 2007). Plant height in SPs covered by Spiraea pubescens Turcz is the highest in average among the four types of SPs, which is over $77 \mathrm{~cm}$. However, the canopy cover, especially the basal cover, of Spiraea pubescens Turcz covered SPs is lower than those of beard grass and Artemisia sacrorum.

Antecedent soil moisture $(A S M)$ is an important initial condition for runoff generation and sediment production for each rainfall event. However, as all the MPs were located on the same hillslope, the similar slope position, and aspect, the ASM was not significantly varied among MPs (Figure 4).

During the 10-month monitoring period, 11 events were observed with runoff generation occurred for all SPs. Twelve rainfall events with runoff collected for all the five MPs occurred in the same period. The observed total runoff

Table 1 Vegetation coverage and soil properties of the MPs

\begin{tabular}{|c|c|c|c|c|c|}
\hline & Plot 1 & Plot 2 & Plot 3 & Plot 4 & Plot 5 \\
\hline Cover $(\%)$ & 76.0 & 69.8 & 74.3 & 86.6 & 92.1 \\
\hline Plot length (m) & 5 & 5 & 9 & 13 & 13 \\
\hline Projected plot area $\left(\mathrm{m}^{2}\right)$ & 8.91 & 9.34 & 16.04 & 23.83 & 23.17 \\
\hline$T N(\%)$ & $0.12( \pm 0.015)$ & $0.09( \pm 0.021)$ & $0.12( \pm 0.029)$ & $0.10( \pm 0.011)$ & $0.12( \pm 0.015)$ \\
\hline$S O C\left(\mathrm{~g} \mathrm{~kg}^{-1}\right)$ & $16.97( \pm 5.31)$ & $18.03( \pm 5.08)$ & $15.79( \pm 3.77)$ & $20.22( \pm 8.30)$ & $16.56( \pm 4.58)$ \\
\hline$T P\left(\mathrm{~g} \mathrm{~kg}^{-1}\right)$ & $0.64( \pm 0.01)$ & $0.63( \pm 0.01)$ & $0.64( \pm 0.02)$ & $0.62( \pm 0.02)$ & $0.66( \pm 0.02)$ \\
\hline
\end{tabular}


Table 2 Properties of SPs

\begin{tabular}{|c|c|c|c|c|}
\hline \multirow{2}{*}{ SP } & \multirow{2}{*}{ Slope $\left(^{\circ}\right)$} & \multicolumn{2}{|c|}{ Coverage } & \multirow{2}{*}{ Plant height $(\mathrm{cm})$} \\
\hline & & Basal cover $(\%)$ & Canopy cover $(\%)$ & \\
\hline Beard grass 1 & 19 & 70 & 70 & 20 \\
\hline Beard grass 2 & 19 & 85 & 85 & 20 \\
\hline Beard grass 3 & 18 & 90 & 90 & 20 \\
\hline Spiraea pubescens Turcz 1 & 17 & 5 & 77 & 80 \\
\hline Spiraea pubescens Turcz 2 & 18 & 5 & 70 & 120 \\
\hline Spiraea pubescens Turcz 3 & 16 & 8 & 75 & 77 \\
\hline Artemisia sacrorum 1 & 15 & 20 & 86 & 50 \\
\hline Artemisia sacrorum 2 & 14 & 44 & 97 & 52 \\
\hline Artemisia sacrorum 3 & 17 & 33 & 83 & 48 \\
\hline Bare soil 1 & 17 & - & - & - \\
\hline Bare soil 2 & 18 & - & - & - \\
\hline Bare soil 3 & 18 & - & - & - \\
\hline
\end{tabular}
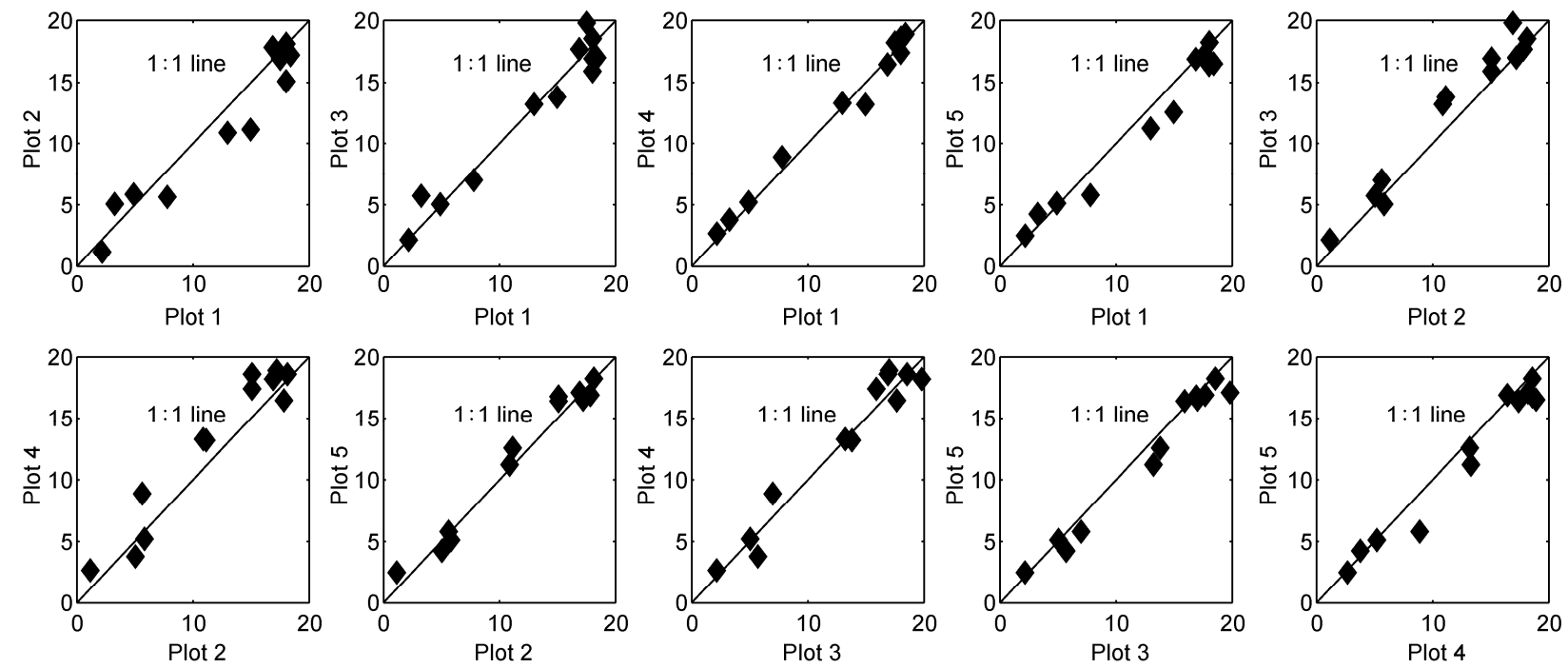

Figure 4 Comparison of antecedent soil moisture between MPs.

volume and soil loss of MPs are shown in Figure 5. In this semiarid region, evapotranspiration is high and was reported to reach a high of $60 \%$ for grassland, $93 \%$ for shrub land, and $95 \%$ for forestland (Wang et al., 2008). The average runoff coefficient of vegetated SPs is rather low compared to that of bare soil (Figure 6). The ratios of the runoff coefficients to bare soil for SPs covered by Artemisia sacrorum, beard grass, and Spiraea pubescens Turcz were 0.079, 0.373, and 0.278 , respectively.

\subsection{Relationship of hydrological variables to cover pattern}

In the modified version of $D L I\left(D L I \_\mathrm{M}\right)$ and Flowlength (Flowlength_M), the weight $(W)$ was integrated, which combines the distance to the outlet and the function of cover to retain water flow and sediment. The average ratio of the runoff coefficient to that of bare soil was used as an indicator of retention capacity of each cover type. The correlation analysis was used to test the efficiency of the four indices. Though $D L I$ was reported to have a positive effect on total runoff volume in a Mediterranean environment (Bautista et al., 2007), no significant correlation between them was found in this study. $D L I \_\mathrm{M}$, the modified version of $D L I$, is significantly correlated to total runoff volume (Figure 7). Flowlength_M, the revised version of Flowlength, also has a positive effect on total runoff. As far as the runoff volume is concerned, the results confirmed the improvement in the ability of the pattern indices to predict runoff and sediments produced. However, none of these indices showed significant correlation to soil loss (Figure 8).

Rainfall characteristics such as rainfall intensity and rainfall depth affect the relationship between vegetation cover pattern and hydrological response. Based on the mean rainfall intensity $(M I)$, the rainfall events were categorized into high intensity events $\left(M I>0.1 \mathrm{~mm} \mathrm{~min}^{-1}\right)$ and low intensity events (with $M I \leqslant 0.1 \mathrm{~mm} \mathrm{~min}^{-1}$ ). Rainfall events are divided into large events (rainfall depth $>50 \mathrm{~mm}$ ), interme- 

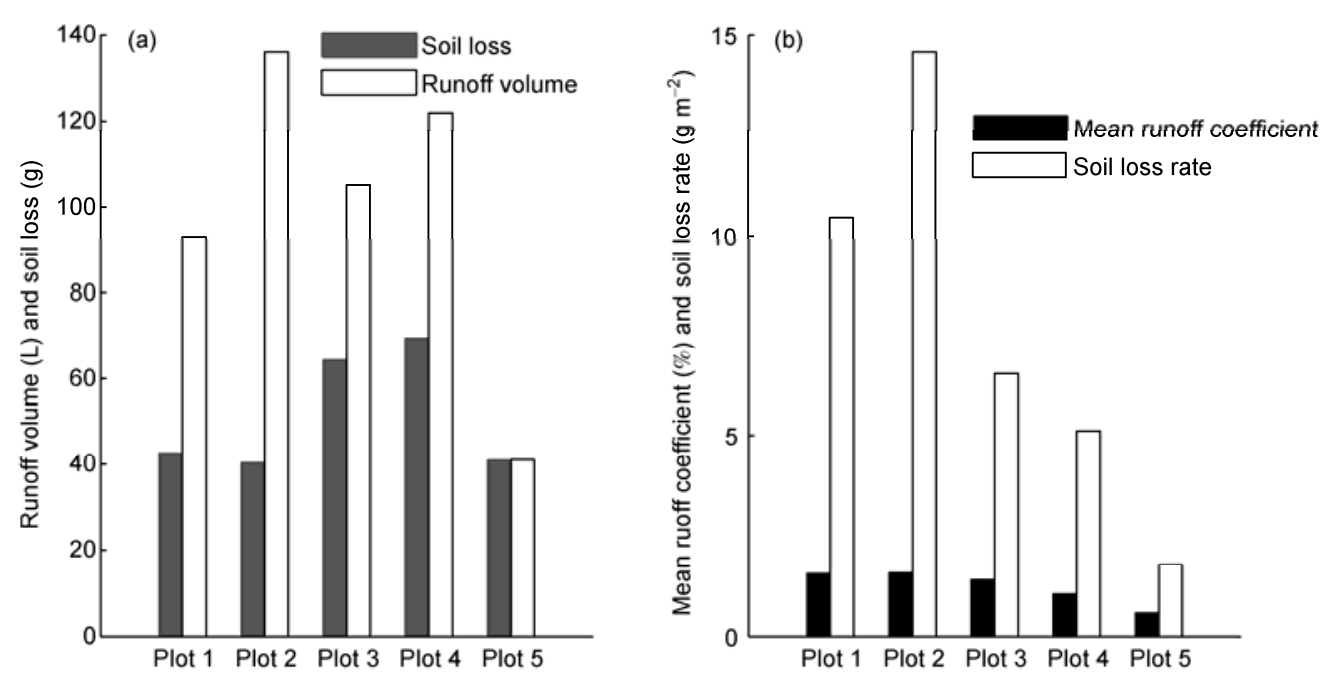

Figure 5 Total runoff and soil loss of the MPs during the observation period.

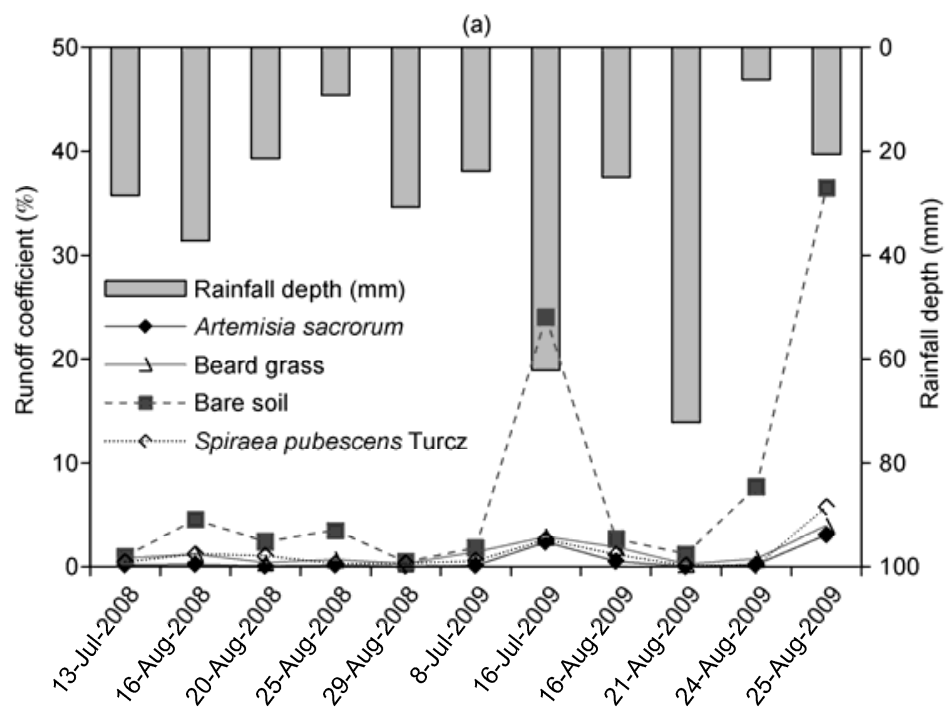

(b)

Figure 6 Runoff coefficient and the ratio to the bare soil of SPs with different cover types.

diate events (rainfall depth $>10 \mathrm{~mm}$ and $\leqslant 50 \mathrm{~mm}$ ), and small events $(\leqslant 10 \mathrm{~mm})$. Figure 9 illustrates the relationship between the total runoff volume and indices for the five types of rainfall events. $D L I$ and Flowlength perform better than DLI_M and Flowlength_M for rainfall events with low intensity (see Figure 9(b)). However, they lost the capability to accurately measure runoff for other types of rainfall events (e.g., Figure 9(a), (c), (d), (e)), especially for large rainfall events. Generally, the modified versions of $D L I$ and Flowlength are better than their antecedents.

\section{Discussion}

\subsection{Efficiency of indices}

Land cover pattern is a control factor of hydrological process at scales from plot/hillslope to landscape level (Imeson and Prinsen, 2004; Boer and Puigdefábregas, 2005; Bautista et al., 2007; Cerdà, 2007; Mayor et al., 2008). Pattern indices have been the widely-used indicators of earth surface processes under a given vegetation cover pattern (Bautista et al., 2007). However, many indices fail to capture important aspects of landscape function (Kupfer, 2012) and are of limited utility in measuring pattern differences (Corry and Nassauer, 2005). The effect of pattern on hydrological processes is obviously different from that on biological processes (e.g., animal migration). Indices commonly used in the field of biology fail to indicate the hydrological consequences of landscape pattern. One of the reasons is the directionality. While animals or plants can potentially move in any direction, the direction of water or soil fluxes depends on topographical gradients (Mayor et al., 2008). Indices developed with heterogeneity in hydrological function of vegetation cover being integrated in are meaningful in linking vegetation cover patterns and hydrological process. 

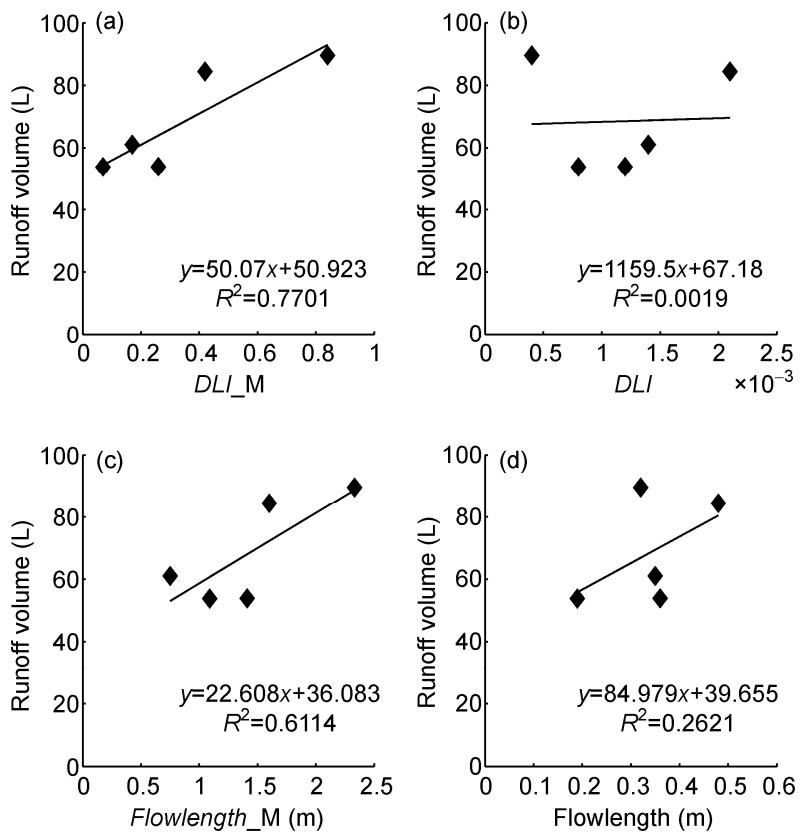

Figure 7 Relationships between cover pattern and runoff volume.
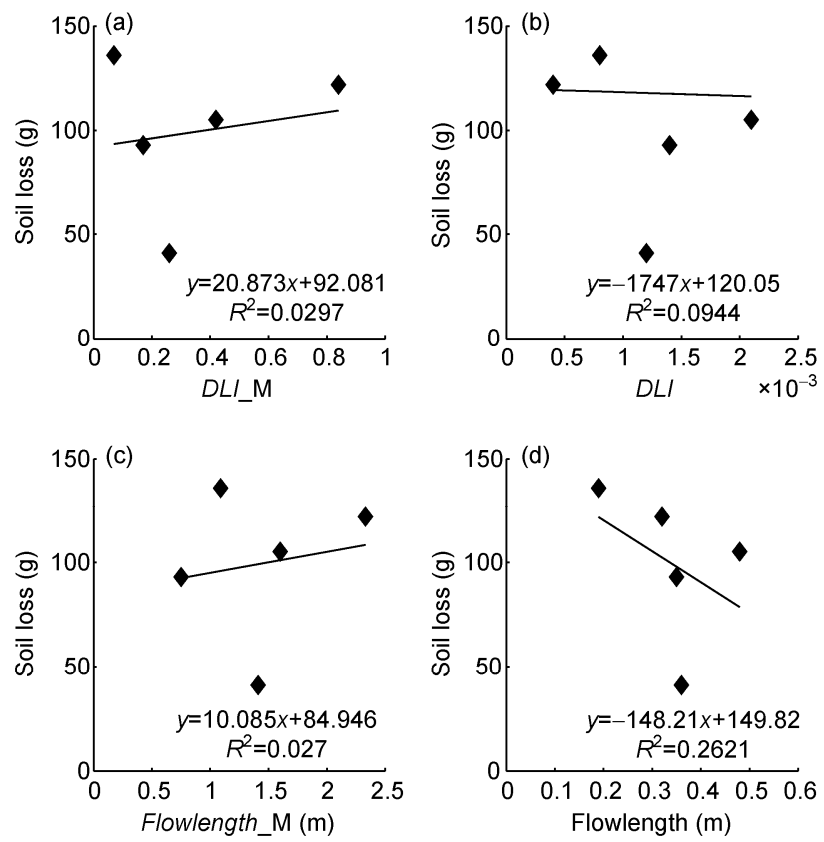

Figure 8 Relationship between cover pattern and soil loss indicated by pattern indices. (a)

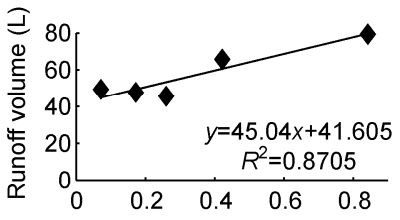

(b)

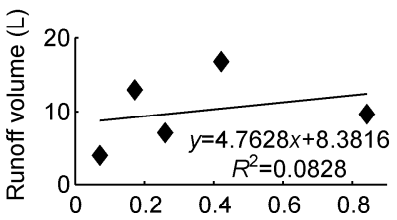

(c)

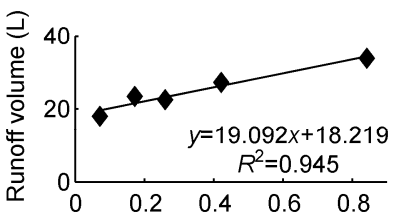

(d)

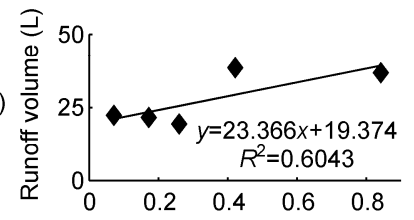

(e)

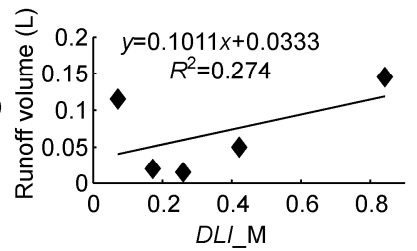

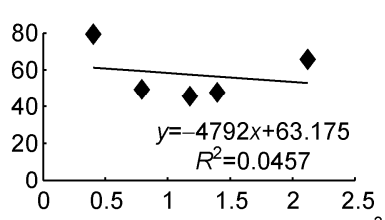

$\left(\times 10^{-3}\right)$

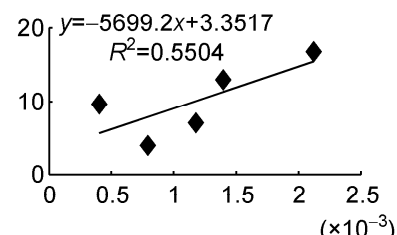

$\left(\times 10^{-3}\right)$
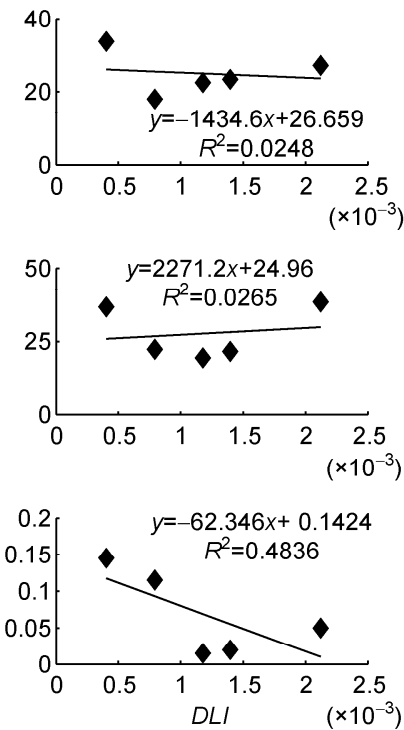
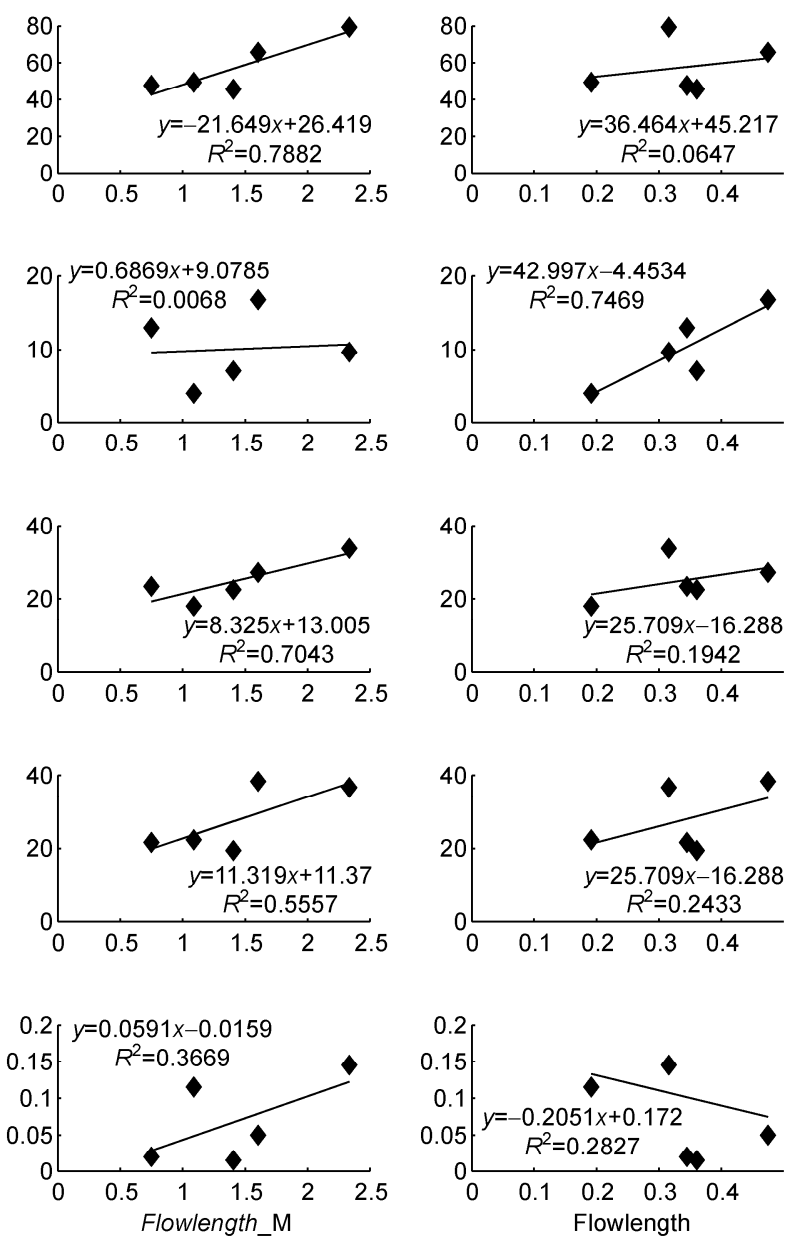

Figure 9 Relationship between cover pattern and runoff under different rainfall characteristics indicated by pattern indices. (a), (b), (c), (d) and (e) refer to rainfall with high intensity, low intensity, large depth, mediate depth and small depth, respectively. 
DLI (Ludwig et al., 2002) and Flowlength (Mayor et al., 2008) are two of them. Both of the two indices reflect hydrological function difference among surface cover types. The covered types are classified into source areas (vegetation patches) and sink areas (bare area). Besides, connectivity of runoff source areas also affects runoff generation and sediment delivery. With more source areas connected along flow pathway, there will be more runoff production and sediment transportation. For DLI, several parameters delineating the connectivity of runoff source areas are incorporated in. Flowlenth essentially is a measure of connectivity of source areas. DLI can clearly position landscapes along a function-dysfunction continuum (Ludwig et al., 2002) and has a positive independent effect on runoff (Bautista et al., 2007). It also was reported that Flowlength correctly ranked the three catchments according to total runoff yield (Mayor et al., 2008).

However, as mentioned above, the functional heterogeneity in vegetation cover and landscape position were not well adopted in DLI and Flowlength. For DLI and Flowlength, all the surface covers of plots are only classified into two functionally contrast types: the vegetated patch and the bare area. However, as reported (Dunjó et al., 2004), and confirmed in this experiment, hydrological effect significantly differs among vegetation cover types. The distance of a specific location to the outlet is one of the factors that affect the observed amount of sediment and runoff. With a large distance to outlet, there are more chances of infiltration and evaporation for runoff (Bracken and Croke, 2007). Moved soil particles also have more opportunity to deposit

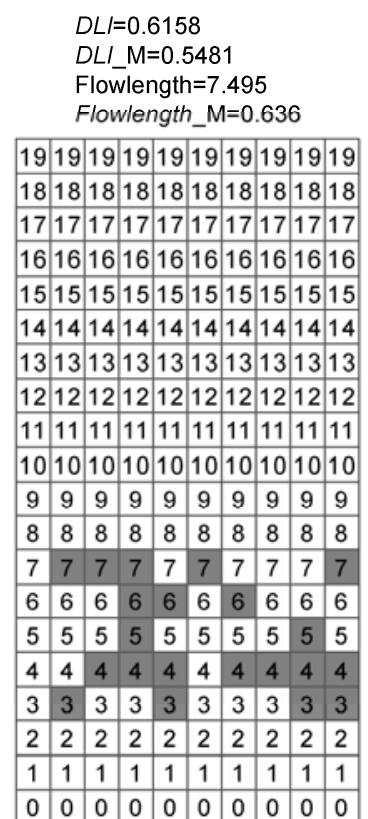

(a)
$D L /=0.6158$

DLI M $=0.6177$

Flowlength $=7.495$

Flowlength_M=1.631

\begin{tabular}{|c|c|c|c|c|c|c|c|c|c|}
\hline 19 & 19 & 19 & 19 & 19 & 19 & 19 & 19 & 19 & 19 \\
\hline 18 & 18 & 18 & 18 & 18 & 18 & 18 & 18 & 18 & 18 \\
\hline 17 & 17 & 17 & 17 & 17 & 17 & 17 & 17 & 17 & 17 \\
\hline 16 & 16 & 16 & 16 & 16 & 16 & 16 & 16 & 16 & 16 \\
\hline 15 & 15 & 15 & 15 & 15 & 15 & 15 & 15 & 15 & 15 \\
\hline 14 & 14 & 14 & 14 & 14 & 14 & 14 & 14 & 14 & 14 \\
\hline 13 & 13 & 13 & 13 & 13 & 13 & 13 & 13 & 13 & 13 \\
\hline 12 & 12 & 12 & 12 & 12 & 12 & 12 & 12 & 12 & 12 \\
\hline 11 & 11 & 11 & 11 & 11 & 11 & 11 & 11 & 11 & 11 \\
\hline 10 & 10 & 10 & 10 & 10 & 10 & 10 & 10 & 10 & 10 \\
\hline 9 & 9 & 9 & 9 & 9 & 9 & 9 & 9 & 9 & 9 \\
\hline 8 & 8 & 8 & 8 & 8 & 8 & 8 & 8 & 8 & 8 \\
\hline 7 & 7 & 7 & 7 & 7 & 7 & 7 & 7 & 7 & 7 \\
\hline 6 & 6 & 6 & 6 & 6 & 6 & 6 & 6 & 6 & 6 \\
\hline 5 & 5 & 5 & 5 & 5 & 5 & 5 & 5 & 5 & 5 \\
\hline 4 & 4 & 4 & 4 & 4 & 4 & 4 & 4 & 4 & 4 \\
\hline 3 & 3 & 3 & 3 & 3 & 3 & 3 & 3 & 3 & 3 \\
\hline 2 & 2 & 2 & 2 & 2 & 2 & 2 & 2 & 2 & 2 \\
\hline 1 & 1 & 1 & 1 & 1 & 1 & 1 & 1 & 1 & 1 \\
\hline 0 & 0 & 0 & 0 & 0 & 0 & 0 & 0 & 0 & 0 \\
\hline
\end{tabular}

(b)

Cell size $=1$

or be trapped by vegetation barriers (Wilcox et al., 2003; Cammeraat, 2004). It was reported that vegetation with a given area positioned near the bottom of a slope is more effective in retaining sediment and runoff at the plot and hillslope scale (Rey, 2004; Li et al., 2008; Ding et al., 2010). These lead to the limited utility of these indices. For example, structurally, the potential to retain runoff and reduce soil erosion of cover patterns shown in Figure 10 is in the order of (a) $>$ (c) $>$ (d) $>$ (b). DLI and Flowlength lost the potential to rank cover patterns that are contrasting in reducing runoff production and soil erosion. While $D L I \_\mathrm{M}$ and Flowlength_M successfully ranked these patterns, this indicates that accounting for the importance of functional heterogeneity and landscape position in cover pattern description can strengthen the predictive potential of pattern indices.

\subsection{Limitations and prospective}

Compared to models, linking landscape pattern with ecological process by pattern indices is a labour-saving approach. Most widely-used pattern indices, such as those included in FRAGSTATS (McGarigal and Marks, 1995; McGarigal et al., 2002), deal with the structure aspects of landscape patterns. They failed to capture important aspects of landscape function (Kupfer, 2012) and have limitations in indicating ecological consequences (Corry and Nassauer, 2005). For hydrological processes that are essentially different from biological process, these indices lost their prediction potentials. Using two revised pattern indices de-

\begin{tabular}{|c|c|c|c|c|c|c|c|c|}
\hline & & or & & & & & & \\
\hline 1 & \begin{tabular}{l|l}
19 & 10
\end{tabular} & & & 9 & & & & 10 \\
\hline 31 & 1818 & & & & & & (1) & 818 \\
\hline 1 & 1717 & & & & & & 1 & \\
\hline 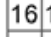 & 1616 & 6 & & 16 & & & 1 & \\
\hline 51 & 1515 & 5 & & 5 & 5 & & & \\
\hline $4 \mid 1$ & & & & & & & & 1 \\
\hline 31 & $\begin{array}{lll}13 & 13 \\
\end{array}$ & 3 & & & & & & 313 \\
\hline 1 & 1212 & 2 & & 2 & & & & 212 \\
\hline 1 & 1111 & 11 & 1 & 11 & 11 & & & 111 \\
\hline 01 & 1010 & 1010 & 10 & 10 & 10 & 10 & 10 & 011 \\
\hline 9 & 99 & 99 & 9 & 9 & 9 & 9 & 9 & \\
\hline 8 & $\begin{array}{ll}8 & 8 \\
\end{array}$ & 88 & 8 & 8 & 8 & 8 & 8 & \\
\hline 7 & \begin{tabular}{l|l}
7 & 7
\end{tabular} & 77 & 7 & 7 & 7 & 7 & 7 & \\
\hline 6 & 66 & 66 & 6 & 6 & 6 & 6 & 6 & \\
\hline 5 & 55 & \begin{tabular}{l|l}
5 & 5 \\
\end{tabular} & 5 & 5 & 5 & 5 & 5 & \\
\hline 4 & 4 & \begin{tabular}{l|l}
4 & 4 \\
\end{tabular} & 4 & 4 & 4 & 4 & 4 & \\
\hline 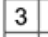 & \begin{tabular}{l|l}
3 & 3 \\
\end{tabular} & \begin{tabular}{l|l}
3 & 3 \\
\end{tabular} & 3 & 3 & 3 & 3 & 3 & \\
\hline 2 & \begin{tabular}{l|l}
22 \\
\end{tabular} & \begin{tabular}{l|l}
22 \\
\end{tabular} & 2 & 2 & 2 & 2 & 2 & \\
\hline & \begin{tabular}{l|l}
1 & 1 \\
\end{tabular} & \begin{tabular}{l|l|}
1 & 1 \\
\end{tabular} & 1 & 1 & 1 & 1 & 1 & \\
\hline & \begin{tabular}{l|l}
0 & 0 \\
\end{tabular} & \begin{tabular}{l|l}
0 & 0 \\
\end{tabular} & & & & & & \\
\hline
\end{tabular}

(c)
$D L I=0.6019$

$D L I M=0.6057$

Flowlength $=6.660$

Flowlength_M=1.379

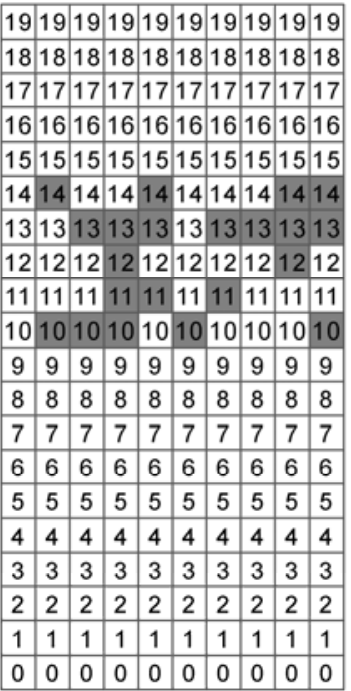

(d)

Figure 10 Response of indices to cover patterns. Assume that the weight for runoff generation potential of vegetation equals 1 , and the bare soil is 2. Numbers in the cells are the elevation. 
signed for hydrological process, we focused on the functional aspects when linking patterns with hydrological processes. The modification in this study improved predictive capabilities of the indices. However, these indices are still far from perfect. Hydrological processes are controlled by the combination of vegetation cover and many other factors including climate, soil properties etc. Antecedent soil moisture $(A S M)$ is one of the influential initial soil hydrological conditions for runoff generation and sediment production. However, ASM was not significantly different between plots (Figure 4).

In a hydrological system, threshold behaviors often exist (Zehe and Sivapalan, 2009), and are scale dependent (Cammeraat, 2004). In addition, nonlinear responses to driving forces are common in hydrological processes (Ludwig et al., 2007; Ryan et al., 2007; McGuire and McDonnell, 2010). Complicated feedback mechanisms between hydrological processes and the biotic and abiotic environments increased the difficulty in predicting hydrological behavior (Zehe and Sivapalan, 2009). If possible, using a series of cover patterns with a time interval may be helpful in capturing feedback mechanisms.

For hydrological processes, also there are many extreme events. Correctly indicating processes during extreme events is an important aspect for an ideal pattern index. Unfortunately, most pattern indices do not address this and focus on cover pattern. They are designed for predicting the processes for average or "normal" events by statically evaluating cover patterns. Though the modified indices in this study do well at predicting total runoff from large rainfall events, this does not imply they will be efficient under extreme events.

\section{Conclusions}

Vegetation cover patterns have dramatic effects on hydrological responses in semiarid environments. In this study, we linked vegetation cover patterns with hydrological responses using two pattern indices: Directional Leakiness (DLI) (Ludwig et al., 2002) and Flowlength (Mayor et al., 2008). These indices distinguished the land cover as two types with contrasting functions, i.e., bare soil and vegetation. They are meaningful in indicating the effect of cover patterns on hydrological processes. However, shortcomings include the neglect of functional differences in hydrological processes among vegetation types and the lack of related landscape position constraint on their potential to predict hydrological responses.

In this study, we improved these indices by incorporating two weight parameters indicating the capability of runoff generation for vegetation cover types and landscape positions. The analysis based on experimental data showed the correction improved the behavior of indices in indicating the potential of sites to retain runoff under different vegeta- tion cover patterns. Comparison analysis using simulated data also showed the modified version of DLI and Flowlength (DLI_M and Flowlength_M) correctly ranked the cover patterns in the function-dysfunction continuum, which demonstrated an apparent improvement of indices.

However, the function aspects included in the pattern description are not completed. In addition, threshold behavior and feedback between hydrological processes and vegetation cover pattern were not taken into account in the design and the correction of these indices. For future improvement, more aspects of landscape function should be included to strengthen the indices. If possible, it makes sense to consider threshold behaviors and feedback mechanisms involved in hydrological processes when applying pattern indices.

This study was supported by the National Natural Science Foundation of China (Grant Nos. 40930528 \& 41101096), and the Chinese Academy of Sciences/State Administration for Foreign Experts Affairs International Partnership Program for Creative Research Teams of "Ecosystem Processes and Services". We sincerely give our thanks to the anonymous reviewers for their constructive comments.

Bautista S, Mayor Á G, Bourakhouadar J, et al. 2007. Plant spatial pattern predicts hillslope runoff and erosion in a semiarid Mediterranean landscape. Ecosystems, 10: 987-998

Boardman J. 2006. Soil erosion science: Reflections on the limitations of current approaches. Catena, 68: 73-86

Boer M, Puigdefábregas J. 2005. Effects of spatially structured vegetation patterns on hillslope erosion in a semiarid Mediterranean environment: A simulation study. Earth Surf Process Landf, 30: 149-167

Borselli L, Cassi P, Torri D. 2008. Prolegomena to sediment and flow connectivity in the landscape: A GIS and field numerical assessment. Catena, 75: 268-277

Bracken L J, Croke J. 2007. The concept of hydrological connectivity and its contribution to understanding runoff-dominated geomorphic systems. Hydrol Process, 21: 1749-1763

Cammeraat E L H. 2004. Scale dependent thresholds in hydrological and erosion response of a semi-arid catchment in southeast Spain. Agric Ecosyst Environ, 104: 317-332

Cerdà A. 1997. The effect of patchy distribution of Stipa tenacissima L. on runoff and erosion. J Arid Environ, 36: 37-51

Corry R C, Nassauer J I. 2005. Limitations of using landscape pattern indices to evaluate the ecological consequences of alternative plans and designs. Landscape Urban Plan, 72: 265-280

de Vente J, Poesen J, Bazzoffi P, et al. 2006. Predicting catchment sediment yield in Mediterranean environments: The importance of sediment sources and connectivity in Italian drainage basins. Earth Surf Process Landf, 31: 1017-1034

Ding W F, Li M, 2010. Experimental study on the effect of slope vegetation distribution variation on runoff and sediment yield in slope gully system (in Chinese). Geograph Res, 29: 1870-1878

Dunjó G, Pardini G, Gispert M. 2004. The role of land use-land cover on runoff generation and sediment yield at a microplot scale, in a small Mediterranean catchment. J Arid Environ, 57: 239-256

Fu B, Zhao W, Chen L, et al. 2006. A multiscale soil loss evaluation index. Chin Sci Bull, 51: 448-456

Imeson A C, Prinsen H A M. 2004. Vegetation patterns as biological indicators for identifying runoff and sediment source and sink areas for semi-arid landscapes in Spain. Agric Ecosyst Environ, 104: 333-342

Jetten V, de Roo A P J. 2001. Spatial analysis of erosion conservation measures with LISEM. In: Harmon R S, Doe W W, eds. Landscape Erosion and Evolution Modelling. New York: Kluwer Academic. 
$429-445$

Jetten V, Govers G, Hessel R. 2003. Erosion models: Quality of spatial predictions. Hydrol Process, 17: 887-900

Kupfer J A. 2012. Landscape ecology and biogeography: Rethinking landscape metrics in a post-FRAGSTATS landscape. Prog Phys Geogr, 36: 400-420

Li Q, Li Z B, Lu K X, et al. 2008. Experimental research on the runoff and sediment production in Loess Hill Gully Region with different vegetation patterns (in Chinese). China Rural Water Hydropower, 4: $100-104$

Li Y, Poesen J, Yang J C, Fu B, et al. 2003. Evaluating gully erosion using $\mathrm{Cs}-137$ and $\mathrm{Pb}-210 / \mathrm{Cs}-137$ ratio in a reservoir catchment. Soil Tillage Res, 69: 107-115

Liu Y, Fu B, Lü Y, et al. 2012. Hydrological responses and soil erosion potential of abandoned cropland in the Loess Plateau, China. Geomorphology, 138: 404-414

Ludwig J A, Bartley R, Hawdon A A, et al. 2007. Patch configuration non-linearly affects sediment loss across scales in a grazed catchment in north-east Australia. Ecosystems, 10: 839-845

Ludwig J A, Bartley R, Hawdon A A, et al. 2007. Patch configuration non-linearly affects sediment loss across scales in a grazed catchment in north-east Australia. Ecosystems, 10: 839-845

Ludwig J A, Wilcox B P, Breshears D D, et al. 2005. Vegetation patches and runoff-erosion as interacting ecohydrological processes in semiarid landscapes. Ecology, 86: 288-297

Ludwig J A, Eager R W, Bastin G N, et al. 2002. A leakiness index for assessing landscape function using remote sensing. Landsc Ecol, 17: 157-171

Mayor Á G, Bautista S, Small E E, et al. 2008. Measurement of the connectivity of runoff source areas as determined by vegetation pattern and topography: A tool for assessing potential water and soil losses in drylands. Water Resour Res, 44: W10423, doi: 10.1029/2007WR006367

McGarigal K, Marks B J. 1995. FRAGSTATS: Spatial pattern analysis program for quantifying landscape structure. General Technical Report PNW-GTR-351, USDA Forest Service, Pacific Northwest Research Station, Portland, OR.

McGarigal K, Cushman S A, Neel M C, et al., 2002. FRAGSTATS: Spatial pattern analysis program for categorical maps. Computer software program produced by the authors at the University of Massachusetts, Amherst.

McGuire K J, McDonnell J J. 2010. Hydrological connectivity of hillslopes and streams: Characteristic time scales and nonlinearities. Water Resour Res, 46, doi: 10.1029/2010WR009341

Molina A, Govers G, Cisneros F, et al. 2009. Vegetation and topographic controls on sediment deposition and storage on gully beds in a degraded mountain area. Earth Surf Process Landf, 34: 755-767

Molina A, Govers G, Vanacker V, et al. 2007. Runoff generation in a degraded Andean ecosystem: Interaction of vegetation cover and land use. Catena, 71: 357-370

Morgan R P C. 2007. Vegetative-based technologies for erosion control. In: Stokes A, Spanos I, Norris J E, et al, eds. Eco- and Ground Bio-Engineering: The Use of Vegetation to Improve Slope Stability.
Dordrecht: Springer. 265-272

Ouyang W, Skidmore A K, Hao F, et al. 2010. Soil erosion dynamics response to landscape pattern. Sci Total Environ, 408: 1358-1366

Pimentel D, Kounang N. 1998. Ecology of soil erosion in ecosystems. Ecosystems, 1: 416-426

Quinton J N, Edwards G M, Morgan R P C. 1997. The influence of vegetation species and plant properties on runoff and soil erosion: results from a rainfall simulation study in south east Spain. Soil Use Manag, 13: $143-148$

Quinton J N. 1997. Reducing predictive uncertainty in model simulations: A comparison of two methods using the European Soil Erosion Model (EUROSEM). Catena, 30: 101-117

Rey F. 2004. Effectiveness of vegetation barriers for marly sediment trapping. Earth Surf Process Landf, 29: 1161-1169

Richard E B, Beven K J, Freer J, et al. 2000. Equifinality and uncertainty in physically based soil erosion models: Application of the GLUE methodology to WEPP - the Water Erosion Prediction Project-for sites in the UK and USA. Earth Surf Process Landf, 25: 825-845

Ryan J G, Ludwig J A, Mcalpine C A. 2007. Complex adaptive landscapes (CAL): A conceptual framework of multi-functional, non-linear ecohydrological feedback systems. Ecolog Complex, 4: 113-127

Sommer M. 2006. Influence of soil pattern on matter transport in and from terrestrial biogeosystems-A new concept for landscape pedology. Geoderma, 133: 107-123

Takken I, Beuselinck L, Nachtergaele J, et al. 1999. Spatial evaluation of a physically-based distributed erosion model (LISEM). Catena, 37: 431-447

Van Dessel W, Van Rompaey A, Poelmans L, et al. 2008. Predicting land cover changes and their impact on the sediment influx in the Lake Balaton catchment. Landsc Ecol, 23: 645-656

Van Rompaey A, Krasa J, Dostal T. 2007. Modelling the impact of land cover changes in the Czech Republic on sediment delivery. Land Use Policy, 24: 576-583

Vasquez-Mendez R, Ventura-Ramos E, Oleschko K, et al. 2010. Soil erosion and runoff in different vegetation patches from semiarid Central Mexico. Catena, 80: 162-169

Wang Y H, Yu P T, Xiong W, et al. 2008. Water-yield reduction after afforestation and related processes in the semiarid Liupan Mountains, Northwest China. J Am Water Res Ass, 44: 1086-1097

Wilcox B P, Breshears D D, Allen C D. 2003. Ecohydrology of a resource-conserving semiarid woodland: Effects of scale and disturbance. Ecol Monogr, 73: 223-239

Yuan Y P, Bingner R L, Locke M A. 2009. A review of effectiveness of vegetative buffers on sediment trapping in agricultural areas. Ecohydrology, 2: 321-336

Zehe E, Sivapalan M. 2009. Threshold behaviour in hydrological systems as (human) geo-ecosystems: Manifestations, controls, implications. Hydrol Earth Syst Sci, 13: 1273-1297

Zhao W W, Fu B J, Chen L D. 2012. A comparison of the soil loss evaluation index and the RUSLE Model: A case study in the Loess Plateau of China. Hydrol Earth Syst Sci, 9: 2409-2442

Zuazo V H D, Pleguezuelo C R R. 2008. Soil-Erosion and runoff prevention by plant covers: A review. Agron Sustain Devel, 28: 65-86 